\title{
Chemosterilants for Control of Insects and Insect Vectors of Disease
}

\author{
Richard H. G. Baxter ${ }^{\star}$
}

\begin{abstract}
Both historically and at present, vector control is the most generally effective means of controlling malaria transmission. Insecticides are the predominant method of vector control, but the sterile insect technique (SIT) is a complementary strategy with a successful track record in both agricultural and public health sectors. Strategies of genetic and radiation-induced sterilization of Anopheles have to date been limited by logistical and/ or regulatory hurdles. A safe and effective mosquito chemosterilant would therefore be of major utility to future deployment of SIT for malaria control. Here we review the prior and current use of chemosterilants in SIT, and assess the potential for future research. Recent genomic and proteomic studies reveal opportunities for specific targeting of seminal fluid proteins, and the capacity to interfere with sperm motility and storage in the female.
\end{abstract}

Keywords: Aziridine $\cdot$ Chemosterilant $\cdot$ Malaria $\cdot$ Sterile-insect technique $\cdot$ Vector-borne disease

\section{Introduction}

Many global infectious diseases are transmitted by insect vectors, and vector control is an efficient means of preventing disease transmission. ${ }^{[1]}$ Since the first use of DTT to control disease transmission in refugee camps at the conclusion of WWII, insecticides have proved tremendously successful in the campaigns to control and eradicate typhus, sleeping sickness, malaria, dengue and other diseases by indoor residual spraying (IRS), insecticide treated nets (ITN) and ultra-low volume (ULV) spraying.

However, the use of insecticides has limitations. Insecticides are distributed over an area; their efficacy is proportional to the number density of vectors in the area. Thus, insecticides are most effective in scenarios of endemic transmission with high vector density, but as vector density

\footnotetext{
${ }^{*}$ Correspondence: Prof. R. H. G. Baxter Department of Chemistry

Dept. of Molecular Biophysics \& Biochemistry Yale University

PO Box 208107, New Haven CT 06520-8107, USA

E-mail: richard.baxter@yale.edu
}

decreases there is a decreasing marginal utility in driving the population to zero. Second, the conventional use of insecticides to cause rapid mortality means susceptible members of the population do not reproduce, creating selective pressure for the development of resistance.

Vectors can develop resistance to insecticides by (i) mutations in the target protein, (ii) metabolic detoxification, or (iii) increased efflux or excretion. They can also develop behavioral resistance by avoiding the point of application. Hence, the use of IRS/ITNs may result in 'cryptic populations' that rest and feed outdoors and are unaffected by existing or future insecticides.

The sterile insect technique (SIT) involves the continuous mass release of sterile individuals that compete with wild individuals for mates, suppressing the population in subsequent generations. ${ }^{[2]}$ As a method of insect control, SIT has several advantages:

- The efficacy of SIT increases with declining population density.

- SIT has, by definition, species-level specificity, with minimal off-target effects.

- SIT has an excellent record for (lack of) resistance.

- Released males seek out 'cryptic populations' of vectors.

SIT has been used to eradicate a number of agricultural pests and in one notable case a human and zoonotic vector, the tsetse fly. ${ }^{[3]}$ SIT can be a powerful component of area-wide integrated pest management (AW-IPM) strategies. ${ }^{[4]}$ However, SIT has not yet been used at an operational level to control mosquitoes (genus Anopheles, Aedes, Culex $)^{[5]}$ - vectors for malaria and the arboviruses such as Dengue,
Chikungunya and Zika - or other vectors such as sandflies (Leishmania) or triatomines (Chagas disease).

SIT uses three methods of inducing sterility: (i) X-ray or $\gamma$ irradiation, (ii) chemosterilization, or (iii) genetic modification (GM). While radiation has been used successfully in a number of flies, including tsetse flies, mosquitoes and a number of other insects suffer a significant loss in fitness at doses required for complete sterilization, and specialized facilities are required for irradiation. ${ }^{[6]}$ The process of GM to produce males carrying a female-specific lethal gene has been greatly accelerated by transgenic technology. ${ }^{[7]}$ GM Aedes mosquitoes were the subject of successful field trials in the Cayman islands and Brazil, ${ }^{[8]}$ and were recently approved by the FDA for release in Florida. Besides regulatory concerns, however, ${ }^{[9]} \mathrm{GM}$ requires a separate laboratory strain for each reproductively isolated vector species or sub-species to be controlled. This may be challenging given the large number of known vectors, or the laboratory strain may lose mating fitness over time due to inbreeding.

Here we discuss the third approach, chemosterilization. A large body of research from the 1960s-70s identified thousands of potential chemosterilants, which can deliver improved fitness compared to radiation. ${ }^{[5 a, 10]}$ Unfortunately, concerns regarding toxicity as well as external factors led to this effort being largely abandoned. In the past 15 years, however, great strides have been made in genetics and molecular analysis of mosquito and other disease vectors. In the hopeful event that interest, and funding, returns to this field such knowledge can be leveraged to develop ever more safe, effective and specific chemosterilants. 


\section{Laboratory and Field Trials of Aziridine-phosphoryl Chemosterilants}

The theory and practice of SIT includes many aspects besides the choice of sterilant that must be considered in an effective campaign. ${ }^{[5 a, 11]}$ The first successful SIT eradication program, using X-ray or $\gamma$ irradiation to sterilize males, targeted the cattle screw worm Callitroga hominivorax. ${ }^{[2 a, 12]}$ When applied to mosquitoes however, radio-sterilized males were not as competitive as normal males. ${ }^{[13]}$ Following pioneering studies in Drosophila, ${ }^{[14]}$ studies in the house fly Musca domestica identified aziridnyl-based DNA alkylating agents, such as apholate (1), as effective chemosterilants (Fig. 1). ${ }^{[15]}$ Similar studies with tepa (2) and thiotepa (3) were pursued in mosquito vectors Aedes aegyptii and Anopheles quadrimaculatus. ${ }^{[16]}$ In a short space of time hundreds of compounds were identified with chemosterilant properties. [17]

The compounds identified bore close resemblance to the early literature on chemotherapy, including alkylating agents, antimetabolites, antibiotics and alkaloids among others. ${ }^{[18]}$ Aziridine-based alkylating agents emerged as effective chemosterilants for mosquitoes. A field trial, using tarsal exposure to tepa or exposure of pupae to thiotepa, successfully suppressed Culex pipiens quinquefasciatus on Seahorse Key, Florida. ${ }^{[19]}$ Additional cage and field trials with Culex pipiens fatigans Wied. were conducted by the WHO/ICMR unit in New Delhi, ${ }^{[20]}$ although infiltration of surrounding fertile females limited efficacy of the trial.[21] Preliminary trials of thiotepa-sterilized Aedes aegypti were also conducted alongside radiation and genetic methods. [22]

A comprehensive field trial for release of Anopheles albimanus chemosterilized by bisazir (4) was conducted by the USDA in El Salvador.[10a-d] The daily mean production was 42,900 pupa. The release of 4.3 million chemosterilized males over a five-month period resulted in a $99 \%$ reduction in the indigenous population, despite migration into the test area. A significant issue with the El Salvador trial was that sex separation on the basis of size was not stringent. Some $14 \%$ of release mosquitoes were female, a potential source of continued disease transmission. The WHO/ICMR project reported an improved physical separation that reduced the number of female Culex pipiens to $<1 \%$ with $91 \%$ recovery of males, although complete elimination of females recovered only $33 \%$ of male pupae. ${ }^{[23]}$

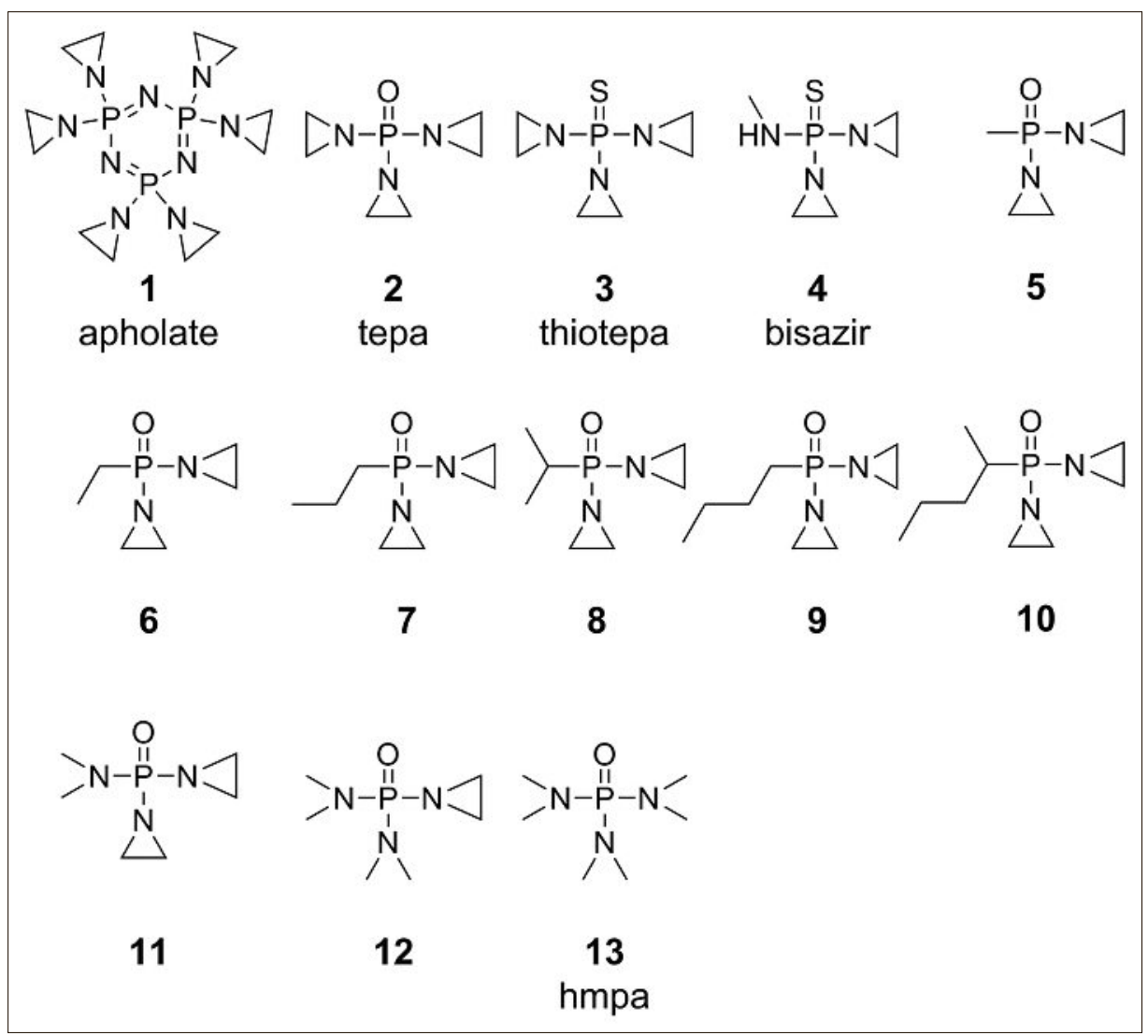

Fig. 1. Aziridine-based chemosterilants.

\section{Toxicology of Aziridine- phosphoryl Chemosterilants}

Aziridine-based chemosterilants, like other DNA alkylating agents, are cytotoxic. A key parameter used to compare effectiveness of compounds is the ratio of the $50 \%$ lethal dose $\left(\mathrm{LD}_{50}\right)$ and $90 \%$ effective dose $\left(E_{90}\right)$. For instance, substitution of tepa with different alkylamino groups had significant impact on both $\mathrm{LD}_{50}$ and $\mathrm{ED}_{90}$ for the sterilization of Musca domestica by direct injection (Table 1). ${ }^{[18]}$ In the El Salvador field trial an $\mathrm{LD}_{10} / \mathrm{ED}_{90}$ ratio of 7.8 was reported for bisazir. ${ }^{[10 \mathrm{~b}]}$

Despite their toxicity, the reactivity of aziridines means they can be rapidly degraded. ${ }^{[24]}$ The half-life of tepa in a neutral

Table 1. Sterilization and toxicity of alkylamino (aziridn-1-yl) phosphine oxides in male house flies $^{[18]}$

\section{Compound}

tris(aziridin-1-yl)phosphine oxide (2)

$R$-amino-bis(aziridin-1-yl)-phosphine oxide

$\mathrm{R}=\operatorname{Methyl}(\mathbf{5})$

$\mathrm{R}=$ ethyl $(\mathbf{6})$

$\mathrm{R}=n$-propyl (7)

$\mathrm{R}=$ isopropyl $(\mathbf{8})$

$\mathrm{R}=n$-butyl (9)

$\mathrm{R}=n$-isopentyl (10)

dimethylamino-bis(aziridin-1-yl)phosphine oxide (11)

bis(dimethylamino)-(aziridin-1-yl)phosphine oxide (12)

tris(dimethylamino)- phosphine oxide (13)

\begin{tabular}{|c|c|c|}
\hline $\mathbf{L D}_{\mathbf{5 0}}(\mathbf{n m o l})^{\mathbf{a}}$ & $\mathbf{E D}_{\mathbf{9 0}}(\mathbf{n m o l})^{\mathbf{b}}$ & $\mathbf{L D}_{\mathbf{5 0}} / \mathbf{E D}_{\mathbf{9 0}}$ \\
\hline 577.5 & 1.4 & 417 \\
\hline & & \\
\hline 153.7 & 1.7 & 88 \\
\hline 324.6 & 2.7 & 119 \\
\hline 11.3 & 8.5 & 1.3 \\
\hline 448.9 & 3.7 & 123 \\
\hline 94.2 & 9.5 & 9.9 \\
\hline 38.0 & 55.5 & 0.7 \\
\hline 430.4 & 3.5 & 122 \\
\hline 30.5 & 22.5 & 1.4 \\
\hline 562.6 & 79.2 & 7.2 \\
\hline
\end{tabular}


aqueous solution decreased from 31 days at $25^{\circ} \mathrm{C}$ to $<0.1$ days at $100{ }^{\circ} \mathrm{C}$. Degradation involves stepwise hydrolysis to phosphate and ethylenimine, with $N$-ethanolaminyl intermediates. At pH 4 tepa is completely degraded in $3 \mathrm{~h}$ although aziridinyl activity was detectable for up to $24 \mathrm{~h}$. Analysis of C. p. fatigans pupae dipped for $3 \mathrm{~h}$ in tepa or thiotepa and rinsed twice with fresh water found a maximum of $<0.5 \mathrm{ng}$ tepa and $80 \mathrm{ng}$ thiotepa in pupae $6 \mathrm{~h}$ post-treatment, $<0.5 \mathrm{ng}$ tepa and $12.0 \mathrm{ng}$ thiotepa $24 \mathrm{~h}$ post-treatment, $2 \mathrm{ng}$ tepa and $10 \mathrm{ng}$ thiotepa in adults $0-6 \mathrm{~h}$ post-emergence, and $<0.5 \mathrm{ng}$ tepa, $<0.25 \mathrm{ng}$ thiotepa $24 \mathrm{~h}$ post emergence. ${ }^{[25]}$ On this basis, an invertebrate predator would need to consume $\sim 25$ adults $0-6 \mathrm{~h}$ post-emergence to receive the $\mathrm{ED}_{90}$ for sterilization obtained for the house fly. A $100 \mathrm{~g}$ rodent would need to consume 5,000 adults $0-6 \mathrm{~h}$ post-emergence to receive $0.5 \mathrm{mg} \mathrm{kg} / \mathrm{day}$, a dose at which mutagenic/teratogenic effects are reported. To receive a dose of $0.5 \mathrm{mg}$ of thiotepa from adults $24 \mathrm{~h}$ post-emergence would require ingestion of two million mosquitoes.

The degradation of aziridines is complicated, however, by the fact that while the stability of the parent compound decreases at low $\mathrm{pH}$, ethylenimine itself - also an alkylating agent - is stabilized at low $\mathrm{pH}$. When spiders were fed on mosquitoes sterilized in tepa and thiotepa as pupae, a diet of 3-5 mosquitoes per week was sufficient to cause a 20-fold reduction in fertility. ${ }^{[26]}$ An improved protocol was developed to remove residual chemosterilant by successive acid and alkaline treatment of pupa.[27]

Nevertheless, public concerns over the health and environmental impacts of thiotepa were a compounding factor in the collapse of the WHO/ICMR project in India. ${ }^{[28]}$ This represents a salutary lesson in the importance of gaining acceptance and support from the community in vector control efforts. ${ }^{[9 c, 29]}$ Recently in the face of impinging threats from Dengue, Chikungunga and Zika virus, mass release of aziridine-sterilized males has been revived as a part of an integrated program for control of Aedes vectors in Cuba. [30]

\section{Non-alkylating Dimethylamines, Non-aziridine Alkylating Agents}

Besides aziridines, several other alkylating agents have been used as chemosterilants. Complete substitution of aziridines in tepa by dimethylamine yields hexamethylphosphoramide, or hmpa (13). While less effective compared to aziridines (Table 1), it's low mammalian toxicity was initially considered advantageous and it was used in field tests to control M. domestica. ${ }^{[31]}$ However, while hmpa is not itself an alkylating agent it is a potent mutagen via nasal inhalation ( $5 \mathrm{ppb}$ ) due to release of formaldehyde upon metabolism by $\mathrm{P} 450$ mono-oxygenases. ${ }^{[32]}$

The alkanesulfonate busulfan (14) is an effective oral sterilant for boll weevils and was readily metabolized after removal from the diet (Fig. 2). ${ }^{[33]}$ In a field trial in Southern Mississippi following a single integrated insecticide and SIT application, the boll weevil population in the eradication zone was suppressed below detectable levels in 203 out of 246 fields, ${ }^{[3]}$ with an estimated chemical release of $100 \mathrm{ng}$ busulfan/weevil or $6 \mathrm{mg}$ per square mile. ${ }^{[34]}$

\section{Juvenile Hormone (JH) Analogs}

$\mathrm{JH}$ is essential for growth and development of insect larval instars. ${ }^{[35]} \mathrm{JH}$ extract was first extracted from Cecropia moths and its application shown to block larval development. ${ }^{[36]}$ A similar extraction from Tenebrio beetles identified derivatives of farnesol, and $\mathrm{JH}$ analogs (JHAs) derived from farnesol and its ac-<smiles>[R]c1ccc2[nH]cc(C(NC(=O)OCc3cnc4ccccc4c3)C(=O)NCC3CC(Br)=NO3)c2c1</smiles>

Fig. 2. Non-aziridine chemosterilants.

id were developed. [37] A potent JHA for Pyrrhocoris apterus, fortuitously discovered on American paper towels, ${ }^{[38]}$ was identified as the methyl ester of todomatuic acid, juvabione (15). ${ }^{[39]}$ By 1971 hundreds of compounds in the general class of insect growth regulators (IGRs) had been synthesized. [35]

Juvabione was shown not only to sterilize Pyrrhocoris females but treated males transferred sterility to their mates, opening the possibility for the use of $\mathrm{JH}$ analogs as chemosterilants. ${ }^{[40]}$ However, the level of efficacy as a chemosterilant does not generally translate to other families of insects, ${ }^{[41]}$ or male sterilization. However, IGRs found significant utility as larvicides. Application to mosquito control was rapid due to multiple factors, such as that adults are the only harmful stage and larval life cycles are synchronized in periodically flooded habitats. ${ }^{[42]}$ The JHA methoprene (16) was registered for the larval control of floodwater mosquitoes in a slow-release formulation (Altosid ${ }^{\circledR}$ SR10) in 1973.[43]

In the 1980s a new JHA with improved

$(+)$-juvabione

pyriproxyfen 
efficacy was developed by Sumitomo Chemical Co., S-31183 or pyriproxyfen (17). ${ }^{[44]}$ Pyriproxyfen is an effective larvicide at $0.005-0.05 \mathrm{ppb}$ for mosquitoes and a chemosterilant for tsetse flies. ${ }^{[45]}$ Exposure to pyriproxyfen significantly reduces female fecundity in mosquitoes by interfering with egg maturation in females or through transfer to the larval habitat when eggs are laid. [46] Pyriproxyfen's excellent hazard profile $\left(\mathrm{LD}_{50}>5000 \mathrm{mg} / \mathrm{kg}\right.$, no genotoxic or reproductive toxicity observed up to $100 \mathrm{mg} / \mathrm{kg}, t_{1 / 2} \sim 16$ days in water) support its use as in the environment. ${ }^{47]}$ A recent proposed strategy, 'boosted' SIT, is to dust radiation-sterilized males with pyriproxyfen prior to release.[48] In this approach, released males suppress the population by three means: (i) direct competition with viable males for females, (ii) suppression of fecundity in females who copulate with released males, and (iii) suppression of egg development via contamination of larval habitats by females who copulate with released males.

A second strategy is the treatment of bednets with pyriproxyfen. Exposure of $A$. gambiae to nets treated with $0.01 \%$ pyriproxyfen $\left(<10 \mathrm{mg} / \mathrm{m}^{2}\right)$ for $3 \mathrm{~min}$, either before or after a blood meal, resulted in complete sterilization with no eggs laid, including after subsequent blood meals. [49] In a separate study of $A$. arabiensis, total sterility was observed upon 30 min exposure to pyriproxyfen $24 \mathrm{~h}$ after blood feeding but not $72 \mathrm{~h}$ prior to, or 24-72 h after, blood feeding. ${ }^{[50]}$ Deploying pyriproxyfendusted cloths within test huts, a $96 \%$ reduction in adult production vs. control was observed in semi-field conditions. ${ }^{[51]}$

\section{Chitinase Inihibitors}

Chitin is an essential component of insect exoskeletons, which are synthesized and shed at multiple stages of development. Hence, inhibitors of chitin synthesis are potent larvicides. In the early 1970s the development of diflubenzuron (18) or Dimilin $^{\circledR}$ (TH 6040), marked a new class of insecticides, the benzoylphenyl ureas. ${ }^{[34,52]}$ Diflubenzuron has low toxicity $\left(\mathrm{LD}_{50}\right.$ $>2000 \mathrm{mg} / \mathrm{kg}$, no genotoxic or reproductive toxicity observed), although hemotoxicity is noted upon chronic administration at $2 \mathrm{mg} / \mathrm{kg} .{ }^{[47 \mathrm{a}]}$ However, diflubenzuron displays significant toxicity towards marine invertebrates, ${ }^{[53]}$ so it is not suitable for dissemination in aquatic habitats.

Busulfan incompletely sterilizes female boll weevils; co-application of diflubenzuron significantly decreased fertility. ${ }^{[54]}$ Male boll weevils are sterilized if fed a diet containing diflubenzuron by inhibition of sperm transfer or transfer of the chemosterilant to females by contact.
Combined diflubenzuron treatment and irradiation of males was tested in field trials. ${ }^{[55]}$ However, female sterility from diflubenzuron diminishes rapidly as the compound is removed. ${ }^{[56]}$

An innovative recent application of the benzoylphenyl urea lufenuron (19) in the form of a bait gel has been used to control the Mediterranean fruit fly Cerratitis capitata. ${ }^{[57]}$ Lufenuron is used to control fleas, which are themselves vectors of numerous diseases including plague.[58] Chitin synthesis inhibitors have been tested as larvicides against mosquitoes, ${ }^{[59]}$ but have never been used as chemosterilants for hematophagous insects in the field.

\section{Targeting Male Seminal Fluid Proteins}

The past two decades have seen a revolution in genomic and proteomic analysis of insect vectors provide the opportunity of targeted chemosterilants for vector control of hematophagous insects such as mosquitoes and tsetse flies. ${ }^{[60]}$ Analysis of A. gambiae seminal fluid proteins identified a male-specific transglutaminase, AgTG3 that crosslinks a substrate, Plugin, to form a mating plug that is transferred to the female, is necessary for sperm storage. [61] Biochemical characterization of AgTG3 revealed the protein is a homolog of mammalian blood-clotting Factor XIII, identified preferred crosslinking sites in the $30 \mathrm{kDa}$ C-terminal of the substrate Plugin, and established a fluorescent plate-based assay for AgTG3 activity. ${ }^{[62]}$

A pilot screen of dihydroisoxazole inhibitors identified known inhibitors of human TG2 with $\mathrm{IC}_{50}<10 \mu \mathrm{M}$ (20). Administration of AgTG3 inhibitors to A. gambiae males by intrathoracic injection led to a $15 \%$ reduction in mating plug transfer in laboratory mating assays. ${ }^{[63]}$ Whether the inhibitors can be improved or not, however, this approach was abandoned as it is apparent that mating plug formation and AgTG3 is not conserved, even within the Anopheles genus. ${ }^{[64]}$

A. gambiae seminal fluids are rich in 20-hydroxyecdysone (20E), which upon sexual transfer interacts with a female protein, Mating-Induced Stimulator of Oogenesis (MISO), to stimulate oogenesis, ${ }^{[65]}$ suggesting inhibitors of 20E-MISO interaction could be potential chemosterilants. However, male 20E production and transfer in seminal fluids has co-evolved with plug formation, ${ }^{[66]}$ hence again is likely too specific a target to justify development.

\section{Conclusions}

The sterile insect technique is a powerful complement to insecticides and other approaches in an AW-IPM strategy for vector control. Alongside irradiation and genetic modification, chemosterilization is a method of mass-producing sterile males for release. Yet chemosterilization has not been deployed at an operational scale for control of insect disease vectors.

This fact illustrates the challenge of finding a small molecule that can simultaneously fulfill all the requirements of an operational chemosterilant: (i) available at low-cost/high-volume, (ii) produce lifetime sterility upon exposure of larvae in water (mosquitoes) or topical application, (iii) minimal impact on survival and competitiveness of treated males with wild, fertile males, (iv) sufficiently low toxicity to humans to eliminate occupational safety concerns for workers, and (v) easy removal, rapid degradation and low toxicity so as to represent a minimal environmental hazard.

After fifty years of research in the field two such agents identified to date are the aziridines thiotepa and bisazir, which fulfilled requirements (i-iii) and to some minds (iv,v), but were abandoned in the 1970s due to fallout/lingering concerns of toxicity to humans and invertebrate predators of released males. A third agent is pyriproxyfen, which fulfills all criteria but (ii) since it is itself a larvicide. However, pyriproxyfen may well find use in a 'boosted' SIT or in combination with insecticides in IRS/ITN applications.

I suggest several paths by which small molecules could significantly complement or enhance new SIT programs for vector control:

1) Reassess aziridines. Cessation of USDA bisazir field trials in El Salvador and WHO/ICMR thiotepa trials in Delhi were influenced by geopolitical factors. Simple protocols can eliminate chemical residues. This original strategy is worth reconsidering, if new field trials include ecological studies of local predator populations and chemical releases to the environment.

2) Other DNA alkylating agents. Many new agents have been developed in the past 30 years of anti-cancer drug discovery, e.g. minor groove alkylating agents, ${ }^{[67]}$ which could have improved efficacy and/or toxicological profile over thiotepa and bisazir.

3) Targeting spermatogenesis. Only cursory efforts have been made so far at leveraging recent research on male development in insects. Potential targets are spermatogenesis, sperm motility, and seminal fluid proteins. A target specific to, but conserved within, Diptera 
would be ideal as compounds directed against it could be of use against all the dominant vector species: mosquitoes, sandflies, and true flies (house flies, tsetse flies).

4) Female-specific larvicide. A significant hurdle in SIT for mosquito control is sex separation, since females are responsible for disease transmission. Physical separation of pupa is not $100 \%$ effective and release of females is not acceptable in endemic transmission zones. A female-specific larvicide could solve this problem and greatly simplify the logistics of implementing mosquito SIT.

5) Anti-parasitic compounds. An alternative to a female-specific larvicide is a compound that induces resistance to infection by the target pathogen. If treated females were unable to transmit disease, the small percentage released alongside sterile males would not represent a risk for transmission. Compounds stimulating the insect's immune system could fulfil such a role. The essential question is, given there has never been an operational SIT campaign for vector control relying on chemosterilants, whether funding exists to support future research in this area. Yet the choice is not of one strategy vs. another. Chemosterilization is compatible, if not synergistic with irradiation, transgenic, and biological controls to develop operational SIT programs. ${ }^{[68]}$ All strategies should be on the table in the future fight to control, eliminate and ultimately eradicate vector-borne diseases.

\section{Acknowledgements}

This work was supported in part by National Institute of General Medical Sciences (1R01GM114358) of the National Institutes of Health.

Received: July 1, 2016

[1] K. R. Matthews, Science 2011, 331, 1149.

[2] a) R. C. Bushland, A. W. Lindquist, E. F. Knipling, Science 1955, 122, 287; b) J Koyama, H. Kakinohana, T. Miyatake, Annu. Rev. Entomol. 2004, 49, 331; c) A. S. Robinson, Mutat. Res. 2002, 511, 113; d) M. J. Vreysen, K. M. Saleh, M. Y. Ali, A. M. Abdulla, Z. R. Zhu, K. G. Juma, V. A. Dyck, A. R. Msangi, P. A. Mkonyi, H. U. Feldmann, J. Econ. Entomol. 2000, 93, 123; e) E. F. Knipling, 'The Basic Principles of Insect Population Suppression and Management', US Department of Agriculture, Washington D.C., 1979

[3] W. Klassen, C. F. Curtis, in 'Sterile Insect Technique: Principles and Practice in AreaWide Integrated Pest Management', Eds. V. A. Dyck, J. Hendrichs, A. S. Robinson, Springer, Dordrecht, 2005, p. 3.

[4] W. Klassen, in 'Sterile Insect Technique: Principles and Practice in Area-Wide Integrated Pest Management', Eds. V. A. Dyck, J. Hendrichs, A. S. Robinson, Springer, Dordrecht, 2005, p. 39.
[5] a) D. A. Dame, C. F. Curtis, M. Q. Benedict, A. S. Robinson, B. G. J. Knols, Malar. J. 2009 8 Suppl 2, S2; b) L. Alphey, M. Benedict, R. Bellini, G. G. Clark, D. A. Dame, M. W. Service, S. L. Dobson, Vector Borne Zoonotic Dis. 2010, 10, 295.

[6] a) M. E. H. Helinski, A. G. Parker, B. G. J. Knols, Malar. J. 2009, 8 Suppl 2, S6; b) C. F. Oliva, M. Jacquet, J. Gilles, G. Lemperiere, P.O. Maquart, S. Quilici, F. Schooneman, M. J. B. Vreysen, S. Boyer, PLoS One 2012, 7, e49414.

[7] a) D. D. Thomas, C. A. Donnelly, R. J. Wood, L. S. Alphey, Science 2000, 287, 2474; b) F. Catteruccia, J. P. Benton, A. Crisanti, Nat. Biotechnol. 2005, 23, 1414.

[8] a) A. F. Harris, A. R. McKemey, D. Nimmo, Z. Curtis, I. Black, S. A. Morgan, M. Neira Oviedo, R. Lacroix, N. Naish, N. I. Morrison, A. Collado, J. Stevenson, S. Scaife, T. Dafa'alla, G. Fu, C. Phillips, A. Miles, N. Raduan, N. Kelly, C. Beech, C. A. Donnelly, W. D. Petrie, L. Alphey, Nat. Biotechnol. 2012, 30, 828; b) D. O. Carvalho, A. R. McKemey, L. Garziera, R. Lacroix, C. A. Donnelly, L. Alphey, A. Malavasi, M. L. Capurro, PLoS Negl. Trop. Dis. 2015, 9, e0003864.

[9] a) M. Enserink, Science 2010, 330, 1030; b) B. G. J. Knols, R. C. Hood-Nowotny, H. Bossin, G. Franz, A. Robinson, W. R. Mukabana, S. K. Kemboi, Nat. Biotechnol. 2006, 24, 1067; c) M. J. Lehane, S. Aksoy, PLoS Negl. Trop. Dis. 2012, 6, e1495.

[10] a) S. G. Breeland, G. M. Jeffery, C. S. Lofgren, D. E. Weidhaas, Am. J. Trop. Med. Hyg. 1974, 23, 274; b) D. A. Dame, C. S. Lofgren, H. R. Ford, M. D. Boston, K. F. Baldwin, G. M. Jeffery, Am. J. Trop. Med. Hyg. 1974, 23, 282; c) C. S. Lofgren, D. A. Dame, S. G. Breeland, D. E. Weidhaas, G. Jeffery, R. Kaiser, H. R. Ford, M. D. Boston, K. F. Baldwin, Am. J. Trop. Med. Hyg. 1974, 23, 288; d) D. E. Weidhaas, S. G. Breeland, C. S. Lofgren, D. A. Dame, R. Kaiser, Am. J. Trop. Med. Hyg. 1974, 23, 298; e) V. P. Sharma, R. K. Razdan, M. A. Ansari, J. Econ. Entomol. 1978, 71, 449; f) L. M. ElGazzar, D. A. Dame, J. Econ. Entomol. 1983, 76, 1331

[11] S. M. Asman, P. T. McDonald, T. Prout, Annu. Rev. Entomol. 1981, 26, 289.

[12] E. F. Knipling, J. Econ. Entomol. 1955, 48, 459.

[13] A. N. Davis, J. B. Gahan, D. E. Weidhaas, C. N. Smith, J. Econ. Entomol. 1959, 52, 868.

[14] a) C. Auerbach, J. M. Robson, Proc. R. Soc. Edinb. Biol. 1947, 62, 271; b) C. Auerbach, J. M. Robson, J. G. Carr, Science 1947, 105, 243; c) M. J. Bird, Nature 1950, 165, 491.

[15] a) G. C. Labrecque, J. Econ. Entomol. 1961, 54, 684; b) G. C. Labrecque, P. H. Adcock, C. N. Smith, J. Econ. Entomol. 1960, 53, 802; c) G. C. Labrecque, D. W. Meifert, C. N. Smith, Science 1962, 136, 388

[16] a) D. E. Weidhaas, Nature 1962, 195, 786; b) D. A. Dame, H. R. Ford, Nature 1964, 201, 733; c) G. B. White, Nature 1966, 210, 1372.

[17] a) G. C. LaBrecque, in 'Principles of Insect Chemosterilization', Eds. G. C. LaBrecque, C. N. Smith, Appleto-Century-Crofts, New York, 1968, p. 41; b) C. N. Smith, G. C. Labrecque, A. B. Bořkovec, Annu. Rev. Entomol. 1964, 9, 269.

[18] R. B. Turner, in 'Principles of Insect Chemosterilization', Eds. G. C. Labrecque, C. N. Smith, Appleton-Century-Crofts, New York, 1968, p. 159.

[19] a) R. S. Patterson, D. E. Weidhaas, H. R. Ford, C. S. Lofgren, Science 1970, 168, 1368; b) D. E. Weidhaas, Am. J. Trop. Med. Hyg. 1972, 21, 772 .

[20] a) V. P. Sharma, R. S. Patterson, K. K. Grover, G. C. Labrecque, Bull. World Health Organ. 1973, 48, 45; b) V. P. Sharma, R. S. Patterson, G. C. Labrecque, K. R. P. Singh, J. Commun. Dis. 1976, 8, 18.
[21] M. Yasuno, W. W. MacDonald, C. F. Curtis, Jap. J. Sanit. Zool. 1978, 29, 325

[22] K. K. Grover, S. G. Suguna, D. K. Uppal, K. R. P. Singh, M. A. Ansari, C. F. Curtis, D. Singh, V. P. Sharma, K. N. Panicker, Entomol. Exp. Appl. 1976, 20, 8 .

[23] V. P. Sharma, R. S. Patterson, H. R. Ford, Bull. World Health Organ. 1972, 47, 429.

[24] M. Beroza, A. B. Bořkovec, J. Med. Chem. 1964, 7, 44.

[25] G. C. Labrecque, M. C. Bowman, R. S. Patterson, J. A. Seawright, Bull. World Health Organ. 1972, 47, 675.

[26] G. K. Bracken, C. D. Dondale, Can. Entomol. 1972, 104, 1709

[27] V. P. Sharma, Nature 1976, 261, 135.

[28] a) Editorial, Nature 1975, 256, 355; b) J. Hanlon, New Scientist 1975, 68, 102; c) WHO Chron. 1976, 30, 131.

[29] a) P. K. Rajagopalan, K. N. Panicker, WHO Chron. 1986, 40, 184; b) V. P. Sharma, Parasitol. Today 1987, 3, 222.

[30] a) R. Gato, A. Companioni, R. Y. Bruzón, Z. Menéndez, A. González, M. Rodríguez, Acta Trop. 2014, 132, S164; b) R. Gato, R. S. Lees, R. Y. Bruzón, A. Companioni, Z. Menéndez, A. González, M. Rodríguez, Memórias do Instituto Oswaldo Cruz 2014, 109, 365.

[31] a) S. C. Chang, P. H. Terry, A. B. Bořkovec, Science 1964, 144, 57; b) L. D. Shott, A. B. Bořkovec, W. A. Knapp, Toxicol. Appl. Pharm. 1971, 18, 499.

[32] a) G. C. Labrecque, R. L. Fye, Mutat. Res. 1978, 47, 99; b) J. Ashby, P. A. Lefevre, Carcinogenesis 1982, 3, 1273; c) A. M. Sarrif, D. F. Krahn, S. M. Donovan, R. M. O'Neil, Mutat. Res. 1997, 380, 167.

[33] a) W. Klassen, N. W. Earle, J. Econ. Entomol. 1970, 63, 1195; b) D. R. Nelson, J. G. Pomonis, D. L. Cardwell, D. R. Sukkestad, Pestic. Biochem. Phys. 1972, 2, 178.

[34] A. B. Bořkovec, Environ. Health Perspect. 1976, 14,103

[35] K. Sláma, Annu. Rev. Biochem. 1971, 40, 1079.

[36] C. M. Williams, Nature 1956, 178, 212

[37] a) J. H. Law, C. Yuan, C. M. Williams, Proc. Natl. Acad. Sci. USA 1966, 55, 576; b) M. Romaňuk, K. Sláma, F. Šorm, Proc. Natl. Acad. Sci. USA 1967, 57, 349.

[38] K. Sláma, C. M. Williams, Proc. Natl. Acad. Sci. USA 1965, 54, 411.

[39] W. S. Bowers, H. M. Fales, M. J. Thompson, E. C. Uebel, Science 1966, 154, 1020.

[40] P. Masner, K. Sláma, V. Landa, Nature 1968, $219,395$.

[41] G. Benz, Experientia 1971, 27, 581.

[42] a) G. B. Staal, Annu. Rev. Entomol. 1975, 20, 417 ; b) C. H. Schaefer, W. H. Wilder, J. Econ. Entomol. 1973, 66, 913.

[43] a) W. F. Chamberlain, J. Med. Entomol. 1975 12, 395; b) M. S. Mulla, H. A. Darwazeh, J. Econ. Entomol. 1975, 68, 791.

[44] M. Hatakoshi, N. Agui, I. Nakayama, Appl. Entomol. Zool. 1986, 21, 351.

[45] a) P. A. Langley, T. Felton, H. Oouchi, Med. Vet. Entomol. 1988, 2, 29; b) C. H. Schaefer, T. Miura, E. F. Dupras, F. S. Mulligan, W. H. Wilder, J. Econ. Entomol. 1988, 81, 1648; c) M Hatakoshi, H. Kawada, S. Nishida, H. Kisida, I. Nakayama, Jap. J. Sanit. Zool. 1987, 38, 271.

[46] T. Itoh, H. Kawada, A. Abe, Y. Eshita, Y Rongsriyam, A. Igarashi, J. Am. Mosq. Control. Assoc. 1994, 10, 344.

[47] a) FAO/WHO, 'Pesticide residues in food-1999 evaluations. Part II - Toxicological'Geneva, 2000; b) J. Sullivan, 'Environmental fate of pyriproxyfen'Sacramento, 2000.

[48] J. Bouyer, T. Lefrançois, Trends Parasitol. 2014, 30, 271.

[49] K. Ohashi, K. Nakada, T. Ishiwatari, J. Miyaguchi, Y. Shono, J. R. Lucas, N. Mito, J. Med. Entomol. 2012, 49, 1052. 
[50] C. Harris, D. W. Lwetoijera, S. Dongus, N. S. Matowo, L. M. Lorenz, G. J. Devine, S. Majambere, Parasit. Vectors 2013, 6, 144.

[51] D. W. Lwetoijera, C. Harris, S. S. Kiware, G. F. Killeen, S. Dongus, G. J. Devine, S. Majambere, Am. J. Trop. Med. Hyg. 2014, 90, 852.

[52] a) J. L. Marx, Science 1977, 197, 1170; b) L. C. Post, W. R. Vincent, Die Naturwissenschaften 1973, 60, 431; c) A. Verloop, C. D. Ferrell, in 'Pesticide Chemistry in the 20th Century', Vol. 37, Eds. J. R. Plimmer, P. C. Kearney, G. K. Kohn, J. J. Menn, S. Ries, American Chemical Society, Washington D.C., 1977, p. 237.

[53] M. E. Christiansen, J. D. Costlow, R. J. Monroe, Mar. Biol. 1978, 50, 29.

[54] R. F. Moore, H. M. Taft, J. Econ. Entomol. 1975, 68, 96

[55] a) R. F. Moore, R. A. Leopold, H. M. Taft, J. Econ. Entomol. 1978, 71, 587; b) J. E. Wright, J. Roberson, J. R. Dawson, J. Econ. Entomol. 1980, 73,803 .

[56] a) D. L. Bull, G. W. Ivie, Pestic. Biochem. Phys. 1980, 13, 41; b) S. C. Chang, J. Econ. Entomol. 1979, $72,479$.

[57] a) V. Navarro-Llopis, S. Vacas, J. Sanchis, J. Primo, C. Alfaro, J. Econ. Entomol. 2011 104, 1647; b) V. Navarro-Llopis, J. Sanchis, J. Primo-Millo, E. Primo-Yufera, Bull. Entomol. Res. 2007, 97, 359; c) V. Navarro-Llopis, J. Dominguez-Ruiz, M. Zarzo, C. Alfaro, J. Primo, Pest Manag. Sci. 2010, 66, 511.

[58] I. Bitam, K. Dittmar, P. Parola, M. F. Whiting, D. Raoult, Int. J. Infect. Dis. 2010, 14, e667.

[59] a) W. B. Kottkamp, M. V. Meisch, J. Am. Mosq. Control Assoc. 1985, 1, 17; b) J. I. Arredondo-
Jiménez, K. M. Valdez-Delgado, Med. Vet. Entomol. 2006, 20, 377; c) K. W. Lau, C. D. Chen, H. L. Lee, Y. Norma-Rashid, M. SofianAzirun, J. Med. Entomol. 2015, 52, 199; d) D

S. Suman, Y. Wang, A. L. Bilgrami, R. Gaugler, Acta Trop. 2013, 128, 103.

60] W. R. Shaw, G. M. Attardo, S. Aksoy, F. Catteruccia, Curr. Opin. Insect Sci. 2015, 10, 142 .

[61] D. W. Rogers, F. BAldini, F. Battaglia, M Panico, A. Dell, H. R. Morris, F. Catteruccia, PLoS Biol. 2009, 7, e1000272.

[62] B. V. Le, J. B. Nguyen, S. Logarajah, B. Wang, J. Marcus, H. P. Williams, F. Catteruccia, R. H. G. Baxter, J. Biol. Chem. 2012, 288, 4844.

[63] B. V. Le, C. Klöck, A. Schatz, J. B. Nguyen, E G. Kakani, F. Catteruccia, C. Khosla, R. H. G. Baxter, Malar. J. 2014, 13, 210

[64] D. E. Neafsey, R. M. Waterhouse, M. R. Abai, S. S. Aganezov, M. A. Alekseyev, J. E. Allen, J. Amon, B. Arcà, P. Arensburger, G. Artemov, L. A. Assour, H. Basseri, A. Berlin, B. W. Birren, S. A. Blandin, A. I. Brockman, T. R. Burkot, A. Burt, C. S. Chan, C. Chauve, J. C. Chiu, M Christensen, C. Costantini, V. L. M. Davidson, E. Deligianni, T. Dottorini, V. Dritsou, S. B Gabriel, W. M. Guelbeogo, A. B. Hall, M. V. Han, T. Hlaing, D. S. T. Hughes, A. M. Jenkins, X. Jiang, I. Jungreis, E. G. Kakani, M Kamali, P. Kemppainen, R. C. Kennedy, I. K. Kirmitzoglou, L. L. Koekemoer, N. Laban, N. Langridge, M. K. N. Lawniczak, M. Lirakis, N. F. Lobo, E. Lowy, R. M. MacCallum, C. Mao, G. Maslen, C. Mbogo, J. McCarthy, K. Michel, S. N. Mitchell, W. Moore, K. A.
Murphy, A. N. Naumenko, T. Nolan, E. M. Novoa, S. O'Loughlin, C. Oringanje, M. A. Oshaghi, N. Pakpour, P. A. Papathanos, A. N. Peery, M. Povelones, A. Prakash, D. P. Price, A Rajaraman, L. J. Reimer, D. C. Rinker, A. Rokas, T. L. Russell, N. Sagnon, M. V. Sharakhova, T. Shea, F. A. Simão, F. Simard, M. A. Slotman, P. Somboon, V. Stegniy, C. J. Struchiner, G. W. C. Thomas, M. Tojo, P. Topalis, J. M. C. Tubio, M. F. Unger, J. Vontas, C. Walton, C. S. Wilding, J. H. Willis, Y. Wu, G. Yan, E. M. Zdobnov, X. Zhou, F. Catteruccia, G. K. Christophides, F. H. Collins, R. S. Cornman, A. Crisanti, M. J. Donnelly, S. J. Emrich, M. C. Fontaine, W. Gelbart, M. W. Hahn, I. A. Hansen, P. I. Howell, F. C. Kafatos, M. Kellis, D. Lawson, C. Louis, S. Luckhart, M. A. T. Muskavitch, J. M. Ribeiro, M. A. Riehle, I. V. Sharakhov, Z. Tu, L. J. Zwiebel, N. J. Besansky, Science 2015, 347, 1258522.

[65] F. Baldini, P. Gabrieli, A. South, C. Valim, F Mancini, F. Catteruccia, PLoS Biol. 2013, 11, e1001695.

[66] S. N. Mitchell, E. G. Kakani, A. South, P. I. Howell, R. M. Waterhouse, F. Catteruccia, Science 2015, 347, 985.

[67] a) L. R. Ferguson, W. A. Denny, Mutat. Res. 1991, 258, 123; b) L. R. Ferguson, W. A. Denny, Mutat. Res. 2007, 623, 14; c) S. Puyo, D. Montaudon, P. Pourquier, Critical Reviews in Oncology/Hematology 2014, 89, 43.

[68] K. Bourtzis, R. S. Lees, J. Hendrichs, M. J. B. Vreysen, Acta Trop. 2016, 157, 115. 